\title{
Strategic Choice of Market Instrument
}

\author{
Samer Atallah \\ Economics Department, The American University, Cairo, Egypt \\ Email: satallah@aucegypt.edu
}

How to cite this paper: Atallah, S. (2017) Strategic Choice of Market Instrument. Theoretical Economics Letters, 7, 1029-1042. https://doi.org/10.4236/tel.2017.74070

Received: May 24, 2017

Accepted: June 19, 2017

Published: June 22, 2017

Copyright $\odot 2017$ by author and Scientific Research Publishing Inc. This work is licensed under the Creative Commons Attribution International License (CC BY 4.0).

http://creativecommons.org/licenses/by/4.0/

\begin{abstract}
This paper proposes a model where both regulator and industry behave strategically to endogenously choose the optimal market instrument. The regulator payoff function includes political gains from investment in abatement and improvement in the provision of the environmental good in addition to the efficient choice of the instrument level. Whereas the industry's objective is to minimize abatement costs. Under plausible conditions, the model suggests that quantity instrument is favorable to the regulator. Also, industry with high cost of abatement has a better incentive to invest in clean technology. Regulator gains from increasing the provision of environmental good and from industry investing in abatement.
\end{abstract}

\section{Keywords}

Carbon Tax, Quantity, Environmental Policy

\section{Introduction}

The discussions on regulating carbon emissions are still ongoing and have gained momentum recently especially after the publication of important international reports such as the Stern report. One aspect of these discussions is an assessment of the tradable permits system [1]. Another aspect is the comparison between the two distinct alternatives of market instruments to curb emissions: the carbon tax and the cap-and-trade market [2] [3]. The first alternative has been almost absent from political platforms in North America. Even though there have been several policies of taxing carbon emissions within the European Union, carbon trading seems to be the preferred policy. ${ }^{1}$ Several theoretical contributions suggest that price instruments have an advantage over quantity ones. We, however, observe that regulator and industry alike tend to prefer a quantity

${ }^{1}$ The European Emissions Trading Scheme was established in 2005. It is the first and the biggest carbon market worldwide. Prior to that, $\mathrm{SO}_{2}$ market was established in the US under the Acid Rain Program in 1995. 
regime. There is also evidence which suggests that the choice of instrument has possible implications on technological innovation [4] [5] [6]. ${ }^{2}$ This suggests that the regulator may incur a political gain if the choice of instrument increases the incentives for industry to invest in cleaner technology. Additionally, firms may prefer carbon markets. ${ }^{3}$ One potential explanation is that quantity instruments allow industry to keep revenues within the industry rather than transferring them to the government through a price instrument. The research question that this paper addresses is why quantity systems are the outcome of the dynamic process of regulation between regulator and industry. This is relevant research question given the ongoing debate on environmental policy and the corresponding market instrument.

The model builds on the assumption of asymmetric information between the regulator and industry such that the regulator does not know the industry's cost of abatement; whether it has a low or high marginal cost of abatement. It also builds on the dynamic nature of environmental regulation as the regulator updates her information set based on the observed actions of firms. If the regulator observes an investment in abatement, she would use a lower marginal cost schedule to choose the level of regulation. Meanwhile, industry can substitute current gains for future ones in order to minimize the total cost of abatement. Knowing that the regulator may update the regulation in the second period, industry may find an incentive to invest in cleaner technology if this reduces its overall cost of abatement. The regulator's choices are determined by three factors, one economic and two political. The economic payoff is to minimize welfare loss due to under abatement or over abatement. She is also motivated by the political gain if industry engages in investment in abatement. Lastly, regulator payoffs are constrained by the levels of abatement resulting from previous period instruments. The level of abatement in the second period can not be lower than the level of abatement of the first period's instrument.

The model suggests that the interaction between the regulator and industry would result in a separating equilibrium where only the high cost industry invests in abatement and the regulator chooses a quantity system. The main reason behind this result is that abatement investment has many benefits. It reduces the cost of abatement in the second period. It also generates political gains for the regulator and reduces the uncertainty she may have regarding the industry cost of abatement. Also, the intuition is that investment in the first period eliminates welfare loss due to uncertainty. Additionally, the political constraint on the regulator choices increases policy stringency in the case of a price instrument but not in the case of quantity.

This paper complements the literature on dynamic games between regulator and industry in three ways. First, both regulator and industry behave strategi-

\footnotetext{
${ }^{2}$ Additionally, quantity regimes may generate less volatility on the macro level [7].

${ }^{3}$ Examples of permits or quantity markets in North America are based on firms or industries engaging in trading are such as Chicago Climate Exchange, Montreal Climate Exchange, Regional Greenhouse Gas Initiative and Western Climate Initiative.
} 
cally; a notion that is absent in the literature. ${ }^{4}$ The regulator acts strategically by influencing the industry performance and at the same time is influenced by its choices. In other words, the regulator's payoffs are not exclusively determined by the traditional welfare analysis. Her payoff function also depends on the actions of the industry. For instance, it is quite plausible that regulator receives a political gain if firms invest in abatement technologies. It is also plausible that regulator loses politically if she appears to be relaxing regulations vis-à-vis industry. This is particularly true if the updated level of the instrument produces lower level of abatement than if the original level was kept as is.

Second, prior literature used industry previous abatement performance as a means for updating the regulator's information about industry cost of abatement. This model uses actual investment as an observable action that is easier to monitor. The conjecture is that regulator is able of observing investment projects in cleaner or newer technologies that reduce the cost of abatement or the cost of providing environmental goods. Also, observing this type of action would reduce the uncertainty with regards to the cost functions of industry. The optimal choice of market instrument in a dynamic setting is therefore dependent on the changing nature of the cost functions [8] [9] [10].

Lastly, the model presented in this paper is the first model where the choice of instrument is endogenous. Previous literature has compared welfare implications of both market instruments without translating this into an endogenous choice of instrument. This is useful in addressing the main question of this paper which is what makes the choice of quantity or quantity instruments favorable by both regulator and industry?

The comparison between price and quantity instruments has been the subject of several contributions which can be roughly classified into two strings of literature: static and dynamic models. ${ }^{5}$ In a static setting, both instruments are theoretically equivalent in the absence of uncertainty in the cost and benefit functions of abatement. However, under strong assumptions, the uncertainty in the cost function increases the superiority of the price instrument $[11] .{ }^{6}$ Using different assumptions, others have suggested that there is no instrument strictly better than the other and that the policy application should be "time-dependent" [12]. Similarly, the advantage of one instrument over the other depends on how correlated the uncertainty in the benefits and costs function [13].

Not only static models lack a consensus, they also lack the strategic and dynamic aspect of the process of regulation. In dynamic models, regulated firms can act strategically to affect future regulations. Regulator may well use current improved performance as a gauge for more demanding performance in the future (what is referred to as the "ratchet effect"). Industry would clearly have the

${ }^{4}$ The closest model is a model by Weitzman where there is a negotiating process between the regulator and industry [14].

${ }^{5}$ For a comprehensive survey of seminal papers refer to [15] and more recent see [16].

${ }^{6}$ These assumptions are the additive error term, uncertainty in benefits is independent from uncertainty in cost function and quadratic differentiable functional forms of costs and benefits functions. Other papers such as [17] and [18] found similar results when using comparable assumptions. 
incentive to under perform in order to ensure more flexibility in the future [19]. ${ }^{7}$

Other dynamic models consider the impact of stock pollution rather than flow pollutants [].

The starting point in dynamic models is also the presence of uncertainty in cost of abatement. However, the dynamic nature of the model allows the regulator to observe the industry's performance. She can update her belief on the industry's cost of abatement accordingly. This reduces the uncertainty about the cost of abatement. From the standpoint of firms, there would be an incentive to use the performance in the first period to lower the implied regulation in the second period. If they were faced by a permit system, they would have an incentive to under perform, to be granted more permits in the future. The welfare implications would depend on the distribution of high cost firms within the industry [20]. The ability of the regulator to update the quantity instrument could possibly affect its time consistency. As firms learn that regulator would change regulation, regulating through quantity loses its purpose leading to price instrument being a superior instrument [21].

The paper is organized as follows: the following section describes model and its main assumptions. The derivation of the optimal choices of the regulator and industry are in Section 3 and Section 4 respectively. Section 5 entails the optimal choice of instrument. The last section concludes.

\section{Model}

\subsection{Basic Assumptions}

The regulator does not know ahead of time whether industry has a high or low cost of abatement. She does not know whether industry would invest in a new clean technology or would continue with the existing one. She postulates that industry could be represented by two types of firms, a type that has a high marginal cost or another type that has low marginal cost of producing a desirable environmental good such as abatement, $q$ :

$$
M C=M C_{j}(q)
$$

where $j=h, l$ such that:

$$
\frac{\partial M C_{h}}{\partial q}>\frac{\partial M C_{l}}{\partial q}>0
$$

The regulator's expectation of the marginal cost of producing $q$ is therefore:

$$
E(M C)=\pi M C_{h}(q)+(1-\pi) M C_{l}(q)
$$

where $\pi$ is the probability that the industry has a high marginal cost of producing $q$ such that $0<\pi<1$. The social benefit of producing such good has a marginal benefit function that is decreasing in $q$ :

$$
M B=M B(q)
$$

such that:

${ }^{7}$ Other dynamic models such as [22] and [23] consider the impact of stock pollution rather than flow pollutants. 


$$
\frac{\partial M B}{\partial q}<0 \forall q
$$

The potential uncertainty in social benefit function is assumed to be very small or non-existent since the model focuses on how industry and regulator behave strategically. This assumption is sensible given that the previous literature suggests that uncertainty in the benefit function does not affect the "comparative advantage" of one instrument over the other [11]. Other standard assumptions in the literature are also adopted to guarantee an interior solution. There is always an incentive to produce the desired good such that $M B(0)>M C(0)$. Also, there is an incentive to reduce the amount produced $M B(q)<M C(q)$ at high levels of $q$.

The game starts with the regulator choosing the type of instrument based on her payoffs in the game. Then, regulator sets optimal levels based on her belief of the industry cost of abatement. At the end of the first period, industry may decide to invest in abatement technology that would reduce its marginal cost function for every level of $q$ from a high cost function to a low cost function. If the industry is already a low cost industry, investment does not alter its cost function. Investment adds $c(I)$ to its total cost of abatement where $c(I)$ is the level of investment it undertakes and is an increasing function of $I$ such that $c(0)=0$.

At the beginning of the second period, the regulator observes whether an investment in abatement took place or not. In the absence of investment, the regulator uses the same marginal cost function that she used in the first period. Alternatively, if an investment is carried out, the regulator uses the lower marginal cost $M C=M C_{l}(q)$ for every level of $q$. Accordingly, she decides whether to update or to maintain the regulatory levels. Also, the regulator obtains a political gain $G(I)$ where $G(I)$ is an increasing function in $I$ with $G(0)=0$. Finally, industry produces the regulated amount either in a quantity or price system.

\subsection{Flow of Game}

- At the beginning of the first period, regulator has a belief of the cost function of industry based on an expected distribution;

- She chooses whether to impose a price or a quantity instrument;

- Regulator sets the optimal level of regulation;

- Industry observe level of regulation either through price or quantity instrument and decides to invest in abatement technology or not;

- At the beginning of the second period, regulator observes whether industry has undergone an abatement investment or not;

- Regulator decides whether to update or keep optimal levels of previous period. Using backward induction, the flow of the analysis will be as follows: first, solving for the optimal choices of the regulator under each type of instrument in the two periods, then for the industry's optimal choices of abatement and finally for the optimal choice of instrument of the regulator. 


\section{Regulator Optimal Choices}

The regulator's objective is to maximize her welfare function from both periods:

$$
W^{i}=W_{1}^{i}+\delta W_{2}^{i}+G(I)
$$

such that $i=p, q$ where $p$ and $q$ denote price and quantity respectively; the subscripts denote periods 1 and 2 respectively; and $\delta$ is the discount factor. The last term is the political gain if the industry undertakes an investment in abatement. At the beginning of the game, the regulator chooses a quantity instrument if $W_{q}>W_{p}$ and the converse if true. The optimal choice of instrument will be determined using backward induction after analyzing the optimal choices of the regulator and industry (Section 5). In this section, the optimal choices of the regulator are derived under each scenario (price and quantity). The analysis starts by the optimal choice in the first period followed by the optimal choice in the second period.

\subsection{First Period Optimal Choices}

Given the uncertainty about the cost functions of industry, the regulator sets the value of instruments according to her belief $\pi$. Accordingly, at the beginning of the first period, the regulator objective function is to maximize social welfare. Formally, in a quantity system, the regulator problem is:

$$
W_{1}^{q}=\operatorname{Max}_{q_{1}} \int_{0}^{q_{1}}\left(M B(q)-M C_{1}(q)\right) \mathrm{d} q
$$

Such that $M C_{1}(q)=E(M C)$. Similarly, in the case of a price instrument, Equation (2) becomes:

$$
W_{1}^{p}=\operatorname{Max}_{p_{1}} \int_{0}^{q_{1}}\left(M B(q)-M C_{1}(q)\right) \text { d } q \text { s.t. } q=M C_{1}^{-1}(p)
$$

Given the uncertainty about industry's cost function, the regulator uses the expected marginal cost function such that $M C_{1}(q)=E(M C)$. The solution to the above equation is equivalent to equating the marginal social benefit to the expected marginal cost:

$$
M B(q)=E(M C(q))=\pi M C_{h}(q)+(1-\pi) M C_{l}(q)
$$

The solution to the above is the optimal levels of regulations $p_{1}$ and $q_{1}$ for a price and quantity instrument respectively. These levels are depicted graphically by the intersection of both $M B(q)$ and $E(M C(q))$ in Figure $1 .^{8}$

\subsection{Second Period Optimal Choices}

The regulator observes the industry investment decision which reveals information about the industry's marginal cost function in the second period. If industry invests, regulator uses the low marginal cost schedule. In the absence of investment, she uses the expected marginal cost function. Formally:

${ }^{8}$ Figure 1 is an adaptation of a similar model by [12]. 


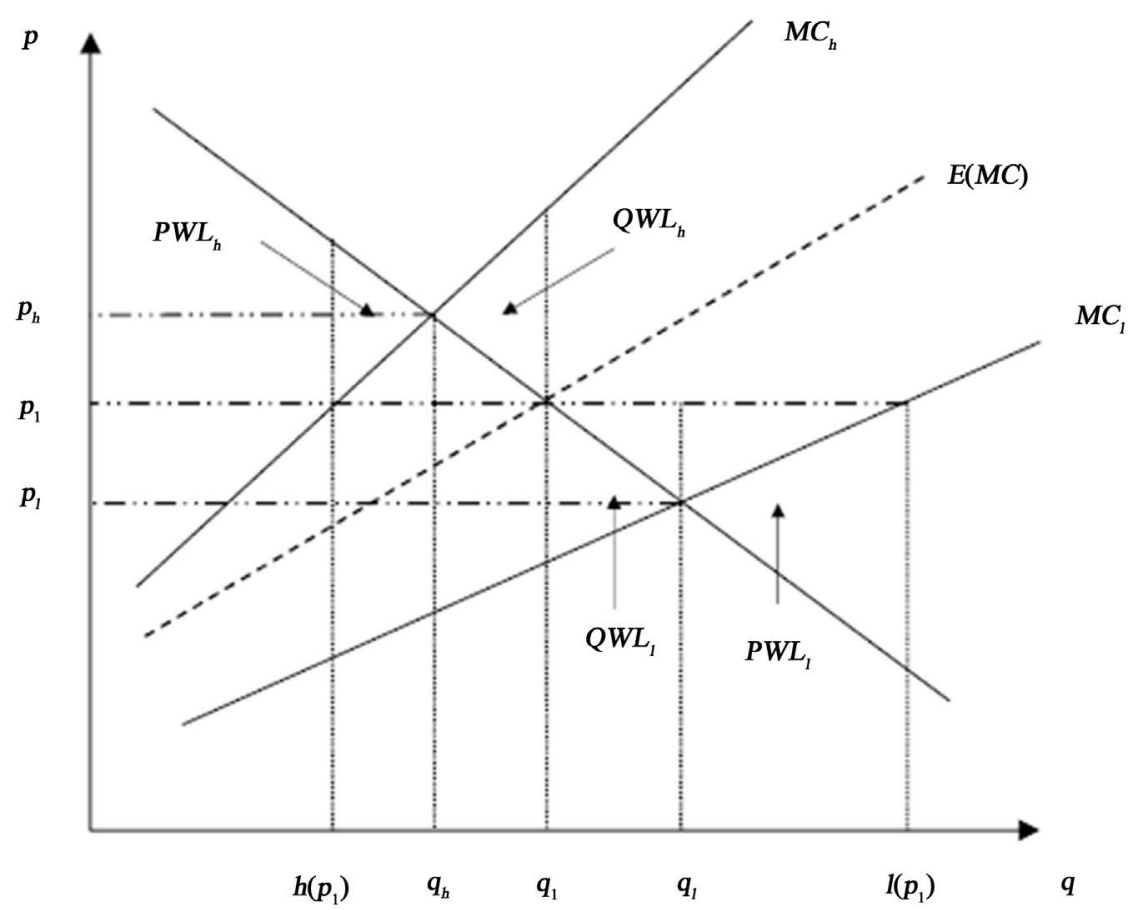

Figure 1. Social welfare and choice of instruments.

$$
M C_{2}(q)= \begin{cases}E(M C) & \text { if } I=0 \\ M C_{l} & \text { if } I>0\end{cases}
$$

such that $M C_{2}(q)$ is the marginal cost function that the regulator uses in the second period.

The choice of the regulator is more complicated in the second period than in the first period. Her choice is either keeping the first period's instrument level and its corresponding level of abatement or increasing it. Her first objective is to minimize the welfare loss due to over or under abatement. However, this objective is constrained by a second objective: level of abatement implied by the second period's instrument can not be lower than the level implied by the first period's instrument.

\subsubsection{Optimal Choices under Quantity Instrument}

Let $\hat{q}_{2}$ be the solution of the unconstrained optimization of Equation (2) and $q_{2}$ be the actual quantity set by the regulator. In other words, $\hat{q}_{2}$ would be the choice of the regulator if she was not constrained by the level of abatement in the first period. Formally:

$$
W_{2}^{q}= \begin{cases}\operatorname{Max}_{q_{2}} \int_{0}^{q_{2}}\left(M B(q)-M C_{2}(q)\right) \mathrm{d} q & \text { such that } q_{2}=\hat{q}_{2} \text { if } q_{2}>q_{1} \\ -\infty & \text { if } q_{2}<q_{1} \\ \int_{q_{2}}^{q_{1}}\left(M B(q)-M C_{2}(q)\right) \mathrm{d} q & \text { if } q_{2}=q_{1}\end{cases}
$$

The first line in the above equation represents the case where the optimal 
choice of Equation (2) does not violate the political constraint. The second line captures the negative payoff due to the political constraint. The last line captures the welfare loss due to over or under abatement resulting from choosing a quantity level that is not optimal to avoid the political constraint.

In the case where industry invests, the unconstrained optimal choice where $M B(q)=M C_{l}(q)$ is $\hat{q}_{2}=q_{l}$ (Figure 1). Since $q_{l}>q_{1}$, the actual choice of the regulator would be $q_{2}=q_{1}$.

If industry does not invest, the unconstrained optimal choice would the solution of $M B(q)=E(M C(q))$ which is $q_{1}$ in Figure 1.

Regulator strategy in the case of a quantity system is as follows:

$$
S_{2}^{q}= \begin{cases}q_{2}=q_{1} & \text { if } I=0 \\ q_{2}=q_{l} & \text { if } I>0\end{cases}
$$

The corresponding welfare loss would be zero either way:

$$
W_{2}^{q}= \begin{cases}0 & \text { if } I=0 \\ 0 & \text { if } I>0\end{cases}
$$

\subsubsection{Optimal Choices under Price Instrument}

The regulator updates her information in the price system as in the quantity system by using Equation (5). She also has the same choices and faces the same constraints. Denoting $p_{2}$ as the actual choice of price and $\widehat{p_{2}}$ as the solution of the unconstrained optimization in Equation (3), the regulator problem is:

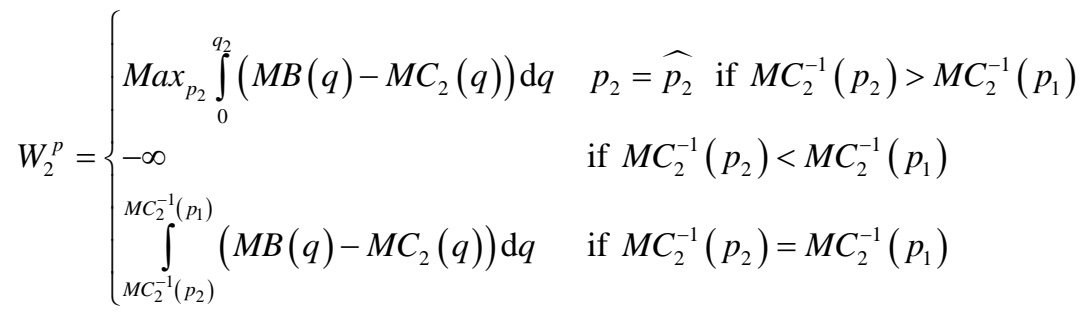

Such that $q=M C_{2}^{-1}(p)$. The reasoning behind each of the above lines is identical to that of Equation (6).

If the firm does not invest, the unconstrained solution to Equation (3) would be:

$$
\hat{p}_{2}=p_{1} \text { such that } \operatorname{MB}\left(q_{1}\right)=\operatorname{EMC}\left(q_{1}\right)
$$

Since $M B\left(q_{1}\right)=E M C\left(q_{1}\right)$, the welfare loss would be zero.

If the firm does invest, the unconstrained optimal choice would be:

$$
\hat{p}_{2}=p_{l} \text { such that } M B\left(M C_{l}^{-1}\left(p_{l}\right)\right)=M C_{l}\left(M C_{l}^{-1}\left(p_{l}\right)\right) \text { if } I>0
$$

In this case, however, the quantity of abatement resulting from $p_{l}$ is lower than that resulting keeping the instrument level at $p_{1}$ :

$$
M C_{l}^{-1}\left(p_{l}\right)<M C_{l}^{-1}\left(p_{1}\right)
$$

Consequently, the regulator can not modify the level of the price instrument and would continue with the previous price instrument $p_{1}$. The resulting welfare loss due to over abatement is $P W L_{l}$ in Figure 1. 
Proposition 1. In a price system, regulator would keep the level of the price instrument at its $p_{1}$ level whether industry invests or not.

Proof. When $I=0$, the expected welfare loss is zero:

$$
W_{2}^{p}=0
$$

Alternatively, if $I>0$ :

$$
W_{2}^{p}= \begin{cases}-_{l\left(p_{l}\right)}^{l\left(p_{1}\right)}\left(M B(q)-M C_{l}(q)\right) \mathrm{d} q & \text { if } p_{2}=p_{1} \\ -\infty & \text { if } p_{2}=p_{l}\end{cases}
$$

It is therefore optimal for the regulator to choose keeping $p_{1}$ when $I>0$.

Therefore, the regulator strategy in the case of a price system is as follows:

$$
S_{2}^{p} \equiv p_{2}=p_{1}
$$

The corresponding payoffs are:

$$
W_{2}^{p}= \begin{cases}0 & \text { if } I=0 \\ -\int_{M C_{l}^{-1}\left(p_{l}\right)}^{M C_{l}^{-1}\left(p_{1}\right)}\left(M B(q)-M C_{l}(q)\right) \mathrm{d} q & \text { if } I>0\end{cases}
$$

It is very important to note here that even though the level of the price instrument is the same in both cases, the welfare implications are different. This is due to the difference in the information set of the regulator. If no investment is observed, the regulator uses the expected marginal cost since she does not have enough information about the type of industry. In the other case, there is an actual investment that reveals the type of industry. However, the regulator is bound by the political constraint (second line in Equation (9)). The welfare loss due to over abatement is preferred to violating the political constraint.

\section{Industry Optimal Choices}

The industry's objective function is to minimize the total cost of producing the $\operatorname{good} q$ :

$$
c_{j}^{i}=c_{1}^{i}+\delta c_{2}^{i}+c(I)
$$

such that such that $i=p, q$ where $p$ and $q$ the type of instrument; $j=h, l$ where $h$ and $l$ denote the type of industry; the subscripts denote the time periods; and $\delta$ is the discount factor. It is assumed that industry abides to the regulator's regulations in both periods. The industry's cost of abatement depends on regulator's decision whether to keep the first period optimal values or to adjust them. The last term is cost of investment in abatement which is the industry's choice variable. The total cost will differ depending on the type of industry. The analysis starts with the high cost industry followed by the low cost industry.

\subsection{High Cost Industry}

\subsubsection{Industry Costs with a Quantity Instrument}

Given that the second period regulation is $q_{1}$ if the firm does not invest or $q_{l}$ 
if the firm does invest (Equation (7)). It follows that total cost of abatement would be:

$$
c_{h}^{q}= \begin{cases}\int_{0}^{q_{1}} M C_{h}(q) \mathrm{d} q+\delta \int_{0}^{q_{1}} M C_{h}(q) \mathrm{d} q & \text { if } I=0 \\ \int_{0}^{q_{1}} M C_{h}(q) \mathrm{d} q+\delta \int_{0}^{q_{l}} M C_{l}(q) \mathrm{d} q+c(I) & \text { if } I>0\end{cases}
$$

Industry would invest in abatement under the following condition:

$$
c(I)<\delta\left(\int_{0}^{q_{1}} M C_{h}(q) \mathrm{d} q-\int_{0}^{q_{l}} M C_{l}(q) \mathrm{d} q\right)
$$

\subsubsection{Industry Costs with a Price Instrument}

Recalling proposition (1), the second period regulation is $p_{1}$ regardless of the industry's action (Equation (10)). It follows that total cost of abatement would be:

$$
C_{h}^{p}= \begin{cases}\int_{0}^{h\left(p_{1}\right)} M C_{h}(q) \mathrm{d} q+\delta \int_{0}^{h\left(p_{1}\right)} M C_{h}(q) \mathrm{d} q & \text { if } I=0 \\ \int_{0}^{h\left(p_{1}\right)} M C_{h}(q) \mathrm{d} q+\delta \int_{0}^{l\left(p_{1}\right)} M C_{l}(q) \mathrm{d} q+c(I) & \text { if } I>0\end{cases}
$$

where $h(p)=M C_{h}^{-1}(p)$ and $l(p)=M C_{l}^{-1}(p)$. Industry would invest if:

$$
c(I)<\delta\left(\int_{0}^{h\left(p_{1}\right)} M C_{h}(q) \mathrm{d} q-\int_{0}^{l\left(p_{1}\right)} M C_{l}(q) \mathrm{d} q\right)
$$

\subsubsection{High Costs Industry Optimal Choices}

From the preceding analysis, the benefit of investing in a cleaner technology is to reduce the marginal cost of abatement. However, moving to a lower marginal cost curve requires producing a higher quantity $q$. The trade off in Equations (13) and (15) is identical. The right-hand side in each equation is the difference between producing a lower quantity at a higher cost or producing a higher quantity at a lower cost. If this difference is greater than the cost of investment, investment becomes viable. If not, industry is better off producing at the higher cost schedule.

Proposition 2. For a given cost of investment, a high cost industry has a better incentive to invest in a quantity system than in a price system.

Proof. The condition for investment under quantity is easier met than the corresponding condition under price if the right hand side of Equation (13) is unambiguously greater than the right hand side of Equation (15). This condition can be expressed as follows.

$$
\int_{0}^{q_{1}} M C_{h}(q) \mathrm{d} q-\int_{0}^{q_{l}} M C_{l}(q) \mathrm{d} q>\int_{0}^{h\left(p_{1}\right)} M C_{h}(q) \mathrm{d} q-\int_{0}^{l\left(p_{1}\right)} M C_{l}(q) \mathrm{d} q
$$

or

$$
\left[\int_{0}^{q_{1}} M C_{h}(q) \mathrm{d} q-\int_{0}^{h\left(p_{1}\right)} M C_{h}(q) \mathrm{d} q\right]+\left[\int_{0}^{l\left(p_{1}\right)} M C_{l}(q) \mathrm{d} q-\int_{0}^{q_{l}} M C_{l}(q) \mathrm{d} q\right]>0
$$

Proof. The first part of the above inequality is the difference of costs of abatement in the first period under the price instrument and a quantity system. Given that $M C_{h}(q)$ is an increasing function in $q$. Using Equation (1) and the assumptions stated before: 


$$
\operatorname{EMC}(q)<M C_{h}(q) \forall q \neq 0 \text { and } \forall 0<\pi<1
$$

Then:

$$
\operatorname{EMC}^{-1}(p)>M C_{h}^{-1}(p) \forall p>M C_{h}(0)
$$

Since $q_{1}=E M C^{-1}\left(p_{1}\right)$ then $q_{1}>M C_{h}^{-1}\left(p_{1}\right)$ or $q_{1}>h\left(p_{1}\right)$. The first part is unambiguously greater than zero since $q_{1}>h\left(p_{1}\right)$. Similarly, and using the same approach, $l\left(p_{1}\right)>q_{l}$. This makes the second part of the above inequality also greater than zero.

The condition in Equation (13) is easier met than condition in Equation (15) for the same parameters and cost of investment because the cost savings under a quantity system are higher than the cost savings under a price system. Either way, the high cost firm would invest in abatement given the strategy of the regulator under the conditions in Equations (13) and (15). The high cost firm strategy is:

$$
\Phi_{h}= \begin{cases}I>0 & \text { under price system } \\ I>0 & \text { under quantity system }\end{cases}
$$

\subsection{Low Cost Industry}

Following the same methodology of analysis as in Equation (12), the corresponding cost is:

$$
c_{l}^{q}= \begin{cases}\int_{0}^{q_{1}} M C_{l}(q) \mathrm{d} q+\delta \int_{0}^{q_{1}} M C_{l}(q) \mathrm{d} q & \text { if } I=0 \\ \int_{0}^{q_{1}} M C_{l}(q) \mathrm{d} q+\delta \int_{0}^{q_{l}} M C_{l}(q) \mathrm{d} q+c(I) & \text { if } I>0\end{cases}
$$

Since $q_{l}>q_{1}$, the cost of abatement with investment in unambiguously higher than the cost of abatement without investment.

Similarly, under a price system, investment only increases cost of abatement.

$$
c_{l}^{p}= \begin{cases}\int_{0}^{l\left(p_{1}\right)} M C_{l}(q) \mathrm{d} q+\delta \int_{0}^{l\left(p_{1}\right)} M C_{l}(q) \mathrm{d} q & \text { if } I=0 \\ \int_{0}^{l\left(p_{1}\right)} M C_{l}(q) \mathrm{d} q+\delta \int_{0}^{l\left(p_{1}\right)} M C_{l}(q) \mathrm{d} q+c(I) & \text { if } I>0\end{cases}
$$

Proposition 3. A low cost industry would not invest regardless of the type of instrument.

Proof. It is clear from Equation (17) and Equation (18), that investment not only adds the cost of investment but also adds cost of abatement.

The intuition behind the above result is that a low cost industry does not benefit from investment in any manner. It does not reduce its marginal cost of abatement since it is already a low cost industry. But more importantly, it does not benefit from lower level of regulation since the regulator does not reduce it in the second period.

\section{Regulator Optimal Choice of Instrument}

The choice of instrument for the regulator is done at the beginning of the first period. Since the game starts by the regulator moving first, she can make her choice based on the choices and actions of industry using backward induction. 
The regulator will therefore compare her payoffs under both systems of regulations and would choose the system that generates the higher payoffs. The first period payoffs are equal since the regulator equates the expected marginal cost function with the marginal benefit function (Equation (4)):

$$
W_{1}^{p}=W_{1}^{q}=0
$$

The equilibrium is a separating equilibrium where high cost industry's strategy is to invest under a quantity and under a price system (Equation (16)) and where the low cost firm does not invest under any system. Recalling that the regulator payoffs under a quantity instrument are $W_{2}^{q}=0$ regardless of the type of instrument (Equation (8)); and the payoffs under price instrument are (from Equation (11)): $W_{2}^{p}=0$ when $I=0$, and, if $I>0$ :

$$
W_{2}^{p}=-\int_{M C_{l}^{-1}\left(p_{l}\right)}^{M C_{1}^{-1}\left(p_{1}\right)}\left(M B(q)-M C_{l}(q)\right) \mathrm{d} q
$$

It follows that the regulator expected payoffs are:

$$
\begin{gathered}
W_{2}^{q}=0 \\
W_{2}^{p}=-\pi \int_{M C_{l}^{-1}\left(p_{l}\right)}^{M C_{1}^{-1}\left(p_{1}\right)}\left(M B(q)-M C_{l}(q)\right) \mathrm{d} q
\end{gathered}
$$

Additionally, there is an expected political gain with a probability $\pi$ in both cases. The total payoff of the regulator is:

$W= \begin{cases}W^{q}=\pi G(I)>0 & \text { under quantity instrument } \\ W^{p}=\pi\left(G(I)-\int_{M C_{l}^{-1}\left(p_{l}\right)}^{M C_{l}^{-1}\left(p_{1}\right)}\left(M B(q)-M C_{l}(q)\right) \mathrm{d} q\right) & \text { under price instrument }\end{cases}$

The regulator would therefore choose to apply a quantity system since $W^{q}>W^{p}$. The equilibrium is such as the regulator chooses a quantity system and the high cost industry invests in abatement while the low cost industry does not.

\section{Conclusions}

The model detailed in this paper adds to the literature on the choice of market instrument using a dynamic game between regulator and industry. Using assumptions about the regulator's payoffs such as her gains from investment abatement and constraints on the choice of regulation in the second period, the model suggests that regulator optimally chooses a quantity instrument rather than a price instrument. In equilibrium, high cost industry invests in abatement to benefit from lower abatement costs. On the other hand, the low cost industry does not since there is no cost savings associated with this decision.

The findings of the model and the paper are limited to the assumptions used, particularly, the shape of the cost function of investment and the political gain function.

\section{References}

[1] Goulder, L.H. (2013) Markets for Pollution Allowances: What Are the (New) Les- 
sons? Journal of Economic Perspectives, 27, 87-102.

https://doi.org/10.1257/jep.27.1.87

[2] Ambec, S. and Coria, J. (2013) Prices vs. Quantities with Multiple Pollutants. Journal of Environmental Economics and Management, 66, 123-140.

https://doi.org/10.1016/j.jeem.2012.11.002

[3] Goulder, L.H. and Schein, A.R. (2013) Carbon Taxes vs. Cap and Trade: A Critical Review. Climate Change Economics, 4, Article ID: 1350010. https://doi.org/10.1142/S2010007813500103

[4] Fischer, C., Parry, I.W.H. and Pizer, W.A. (2003) Instrument Choice for Environmental Protection When Technological Innovation Is Endogenous. Journal of Environmental Economics and Management, 45, 523-545. https://doi.org/10.1016/S0095-0696(03)00002-0

[5] Bergquist, A.-K., et al. (2013) Command-and-Control Revisited: Environmental Compliance and Technological Change in Swedish Industry 1970-1990. Ecological Economics, 85, 6-19. https://doi.org/10.1016/j.ecolecon.2012.10.007

[6] Bergek, A. and Berggren, C. (2014) The Impact of Environmental Policy Instruments on Innovation: A Review of Energy and Automotive Industry Studies. Ecological Economics, 106, 112-123. https://doi.org/10.1016/j.ecolecon.2014.07.016

[7] Dissou, Y. and Karnizova, L. (2016) Emissions Cap or Emissions Tax? A MultiSector Business Cycle Analysis. Journal of Environmental Economics and Management, 79, 169-188. https://doi.org/10.1016/j.jeem.2016.05.002

[8] Malueg, D.A. (1989) Emission Credit Trading and the Incentive to Adopt New Pollution Abatement Technology. Journal of Environmental Economics and Management, 16, 52-57. https://doi.org/10.1016/0095-0696(89)90045-4

[9] McKitrick, R. (1999) A Derivation of the Marginal Abatement Cost Curve. Journal of Environmental Economics and Management, 37, 306-314.

https://doi.org/10.1006/jeem.1999.1065

[10] Requate, T. and Unold, W. (2001) On the Incentives Created by Policy Instruments to Adopt Advanced Abatement Technology If Firms Are Asymmetric. Journal of Institutional and Theoretical Economics, 157, 536-554. https://doi.org/10.1628/0932456012974468

[11] Weitzman, M.L. (1974) Prices vs. Quantities. The Review of Economic Studies, 41, 477-491. https://doi.org/10.2307/2296698

[12] Watson, W.D. and Ridker, R.G. (1984) Losses from Effluent Taxes and Quotas under Uncertainty. Journal of Environmental Economics and Management, 11, 310 326. https://doi.org/10.1016/0095-0696(84)90002-0

[13] Stavins, R.N. (1996) Correlated Uncertainty and Policy Instrument Choice. Journal of Environmental Economics and Management, 30, 218-232. https://doi.org/10.1006/jeem.1996.0015

[14] Weitzman, M.L. (2014) Can Negotiating a Uniform Carbon Price Help to Internalize the Global Warming Externality? Journal of the Association of Environmental and Resource Economists, 1, 29-49. https://doi.org/10.1086/676039

[15] Yohe, G.W. (1977) Comparisons of Price and Quantity Controls: A Survey. Journal of Comparative Economics, 1, 213-233. https://doi.org/10.1016/0147-5967(77)90001-4

[16] Hepburn, C. (2006) Regulation by Prices, Quantities, or Both: A Review of Instrument Choice. Oxford Review of Economic Policy, 22, 226-247. https://doi.org/10.1093/oxrep/grj014

[17] Adar, Z. and Griffin, J.M. (1976) Uncertainty and the Choice of Pollution Control 
Instruments. Journal of Environmental Economics and Management, 3, 178-188. https://doi.org/10.1016/0095-0696(76)90017-6

[18] Roberts, M.J. and Spence, M. (1976) Effluent Charges and Licenses under Uncertainty. Journal of Public Economics, 5, 193-208. https://doi.org/10.1016/0047-2727(76)90014-1

[19] Weitzman, M.L. (1980) The "Ratchet Principle" and Performance Incentives. The Bell Journal of Economics, 11, 302-308. https://doi.org/10.2307/3003414

[20] Moledina, A.A., et al. (2003) Dynamic Environmental Policy with Strategic Firms: Prices versus Quantities. Journal of Environmental Economics and Management, 45, 356-376. https://doi.org/10.1016/S0095-0696(02)00055-4

[21] Biglaiser, G., Horowitz, J.K. and Quiggin, J. (1995) Dynamic Pollution Regulation. Journal of Regulatory Economics, 8, 33-44. https://doi.org/10.1007/BF01066598

[22] Hoel, M. and Karp, L. (2002) Taxes versus Quotas for a Stock Pollutant. Resource and Energy Economics, 24, 367-384. https://doi.org/10.1016/S0928-7655(02)00014-3

[23] Newell, R.G. and Pizer, W.A. (2003) Regulating Stock Externalities under Uncertainty. Journal of Environmental Economics and Management, 45, 416-432. https://doi.org/10.1016/S0095-0696(02)00016-5

Submit or recommend next manuscript to SCIRP and we will provide best service for you:

Accepting pre-submission inquiries through Email, Facebook, LinkedIn, Twitter, etc. A wide selection of journals (inclusive of 9 subjects, more than 200 journals)

Providing 24-hour high-quality service

User-friendly online submission system

Fair and swift peer-review system

Efficient typesetting and proofreading procedure

Display of the result of downloads and visits, as well as the number of cited articles Maximum dissemination of your research work

Submit your manuscript at: http://papersubmission.scirp.org/

Or contact tel@scirp.org 